\title{
Investigation of the Stress-Strain State of Crane Beams in Normal Operating Modes
}

\author{
Vladimir V. Moskvichev and Elena A. Chaban* \\ Special design and technological bureau "Science" \\ Institute of computational technologies SB RAS \\ 53 Mira, Krasnoyarsk, 660049, Russia \\ Krasnoyarsk Institute of Railway Transport \\ Branch of Irkutsk State University of Railway Communications \\ 89 L. Ketskhoveli, Krasnoyarsk, 660028, Russia
}

Received 06.04.2016, received in revised form 27.04.2016, accepted 21.05.2016

The results of finite element studies of the stress-strain state of crane beams in normal operating modes in the absence of fatigue cracks, defects and damages are presented. The distributions of the stress intensity and the component of stress tensor, arisen in the upper zone of crane beams wall along its length under different values of the eccentricity of load, caused by the rail shift from the vertical axis of the beam section, were obtained on the basis of performed calculations. The regularities of stress-strain state of beam wall by a number of factors were determined.

Keywords: crane beam, stress intensity, stress-strain state, fatigue crack, the upper zone of wall.

Citation: Moskvichev V.V., Chaban E.A. Investigation of the stress-strain state of crane beams in normal operating modes, J. Sib. Fed. Univ. Eng. technol., 2016, 9(4), 572-584. DOI: 10.17516/1999-494X-2016-9-4-572-584.

(C) Siberian Federal University. All rights reserved

* Corresponding author E-mail address: sktb@ksc.krasn.ru, chaban_tm@mail.ru 


\title{
Исследование напряженно-деформированного состояния подкрановых балок \\ в штатных режимах эксплуатации
}

\author{
В.В. Москвичев, Е.А. Чабан \\ Специальное конструкторско-технологическое бюро «Наука» \\ Института вычислительных технологий СО РАН \\ Россия, 660049, Красноярск, пр. Мира, 53 \\ Красноярский институт железнодорожного транспорта \\ филиал Иркутского государственного университета путей сообщения \\ Россия, 660028, Красноярск, ул. Л. Кеиховели, 89
}

\begin{abstract}
$\overline{\text { Представлены результаты конечно-элементного исследования напряженно- }}$ деформированного состояния подкрановых балок в штатных режимах эксплуатации при отсутствии усталостных трещин, дефектов и повреждений. По результатам проведенных расчетов получены данные распределения интенсивности напряжений и компонент тензора напряжений, возникающих в верхней зоне стенки подкрановой балки по ее длине при различных величинах эксиентриситета нагружения, обусловленного смещением рельса от вертикальной оси сечения балки. Установлены закономерности напряженнодеформированного состояния стенки балки от ряда факторов.
\end{abstract}

Ключевые слова: подкрановая балка, интенсивность напряжений, напряженнодеформированное состояние, усталостные трещины, верхняя зона стенки.

Для подкрановых балок (ПБ) мостовых кранов режимов работы 7К-8К в условиях циклического нагружения характерно интенсивное накопление повреждаемости и длительные сроки эксплуатации с усталостными трещинами. В этом случае предельное состояние по потере несущей способности возникает путем реализации разрушения на определенной стадии развития усталостных трещин. Долговечность элементов конструкций, в том числе и ПБ, с развивающимися в них трещинами может составлять от 10 до $80 \%$ общей долговечности конструкции [1]. В исследованиях несущей способности ПБ можно выделить три этапа:

- работы 1960-х годов, связанные с анализом напряженно-деформированного состояния (НДС) методами строительной механики и поиском оптимальных конструктивных решений с определением базовых типоразмеров по данным статистической информации о причинах отказов [2-6];

- системные исследования причин отказов в 1980-1990-х годах в связи с оценками долговечности в рамках классических методов теории усталости [7-15];

- в 2000-х годах детальный анализ предельных состояний, живучести и остаточного ресурса по данным технического диагностирования, оптимальных конструктивных форм на базе методов механики разрушения [16-19].

Нормами проектирования СНиП II-23-81* «Стальные конструкции» предусматриваются поверочные расчеты подкрановых конструкций на выносливость, но это не исключает возникновения усталостных трещин уже на ранней стадии эксплуатации. Опыт и результаты технического обследования ПБ, эксплуатируемых в цехах металлургических производств, по-

$$
-573-
$$




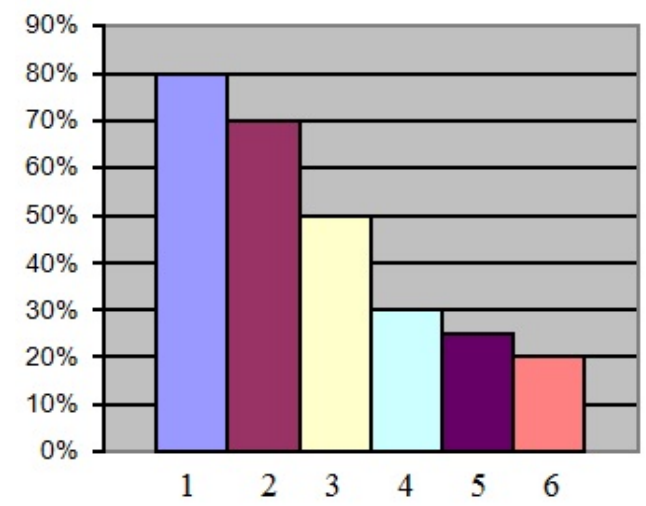

Рис. 1. Характерные повреждения подкрановых конструкций: 1 - нарушение креплений крановых рельсов; 2 - геометрические отклонения крановых путей; 3 - повреждения креплений подкрановых и тормозных балок к колоннам; 4 - возникновение трещин в подкрановых балках; 5 - возникновение трещин в тормозных конструкциях; 6 - недопустимые эксцентриситеты крановых рельсов

казывают, что повреждения, в том числе усталостные трещины протяженностью до 500 мм, возникают уже после 1-3 лет эксплуатации $[6,8,12,16,18]$, в то же время требования РД 10 138-97. «Комплексное обследование крановых путей грузоподъемных машин. Ч. 1 Общие положения. Методические указания» не допускают эксплуатацию с такими повреждениями.

Характерные повреждения подкрановых конструкций показаны на рис. 1. Появление усталостных трещин является одной из причин классификации балок как неработоспособных (более 50 \% обследуемых ПБ), согласно действующим нормам Ростехнадзора. Безусловное выполнение данных требований приведет к массовому выводу ПБ из эксплуатации при сохранении ими несущей способности. В этой ситуации необходим дополнительный анализ остаточного ресурса ПБ с эксплуатационными дефектами. Эта процедура должна регулироваться соответствующими нормативными документами, обязательной процедурой которых должны стать численные исследования напряженно-деформированного состояния (НДС) ПБ в штатных и аварийных ситуациях. Наступление аварийных ситуаций для ПБ возможно вследствие возникновения одиночных повреждений или при возникновении нескольких повреждений различного типа, что позволяет классифицировать аварийную ситуацию как имеющую повышенную степень опасности. Штатные режимы предполагают эксплуатацию ПБ без дефектов и повреждений при уровнях нагрузок, предусмотренных нормативными расчетными случаями.

\section{1. Расчетные схемы и модели подкрановых балок}

Важнейшей составной частью анализа несущей способности ПБ является исследование НДС, в качестве основного инструмента которого в настоящее время выступает конечноэлементное моделирование с использованием соответствующего программного обеспечения. При проведении численного эксперимента применяли программное обеспечение ANSYS 5.7, a в качестве основной характеристики для оценки сложного напряженного состояния - значения интенсивности напряжений $\sigma_{i}$.

В ходе численного эксперимента определялось НДС разрезной подкрановой балки, запроектированной для эксплуатации в электролизном цехе АО «КрАЗ». Электролизный цех осна- 
щен четырьмя мостовыми кранами: три крана грузоподъемностью $10 / 10$ тс режима работы 7К и один кран грузоподъемностью 150/30 тс режима работы 6К. ПБ представляет собой сварной двутавр высотой 1250 мм, длиной 6 м с двумя опорными ребрами и тремя двусторонними ребрами жесткости, расположенными с шагом 1500 мм (рис. $2 a$ ). Балки изготовлены из стали ВСт3сп5-1 согласно ТУ 14-1-3023-80. Расчетные сопротивления данной стали по пределу текучести $\mathrm{R}_{\mathrm{y}}=240 \mathrm{MПа,} \mathrm{по} \mathrm{пределу} \mathrm{прочности} \mathrm{R}_{\mathrm{u}}=360$ МПа. Расчетное сопротивление усталости для сжатой верхней зоны сварной подкрановой балки $\mathrm{R}_{v}=75 \mathrm{MПа;} \mathrm{для} \mathrm{растянутой} \mathrm{верхней}$ зоны стенки сварной подкрановой балки $\mathrm{R}_{v}=65$ МПа. Расчетные значения крановых нагрузок для проектной ПБ приведены в табл. 1. ПБ нагружалась собственным весом, равномерно распределенным по узлам конечно-элементной сетки модели. Масса балки с двусторонними ребрами жесткости с учетом массы наплавленного металла 1565 кг. Так как нагрузка на ПБ передается через подкрановый рельс, то нагружение балки от колеса крана осуществлялось с учетом распределяющего эффекта подкранового рельса, при этом длина участка распределения нагрузки определялась согласно СНиП II-23-81* «Стальные конструкции» и составила $l_{e f}=315$ мм (рис. $\left.2 a\right)$.

Также исследовалась модель ПБ, испытания которой проводили в лаборатории кафедры металлических и деревянных конструкций Новосибирского государственного архитектурностроительного университета (НГАСУ) $[15,20]$ (рис. 2б). Геометрические параметры моделей сварных балок моделировали 6-метровую типовую ПБ в масштабе 1:2. Материал моделей сталь С255 по ГОСТ 27772-88. Поясные швы выполнялись полуавтоматической сваркой в среде углекислого газа сварочной проволокой Св08Г2 с катетом 6 мм. Величина сосредоточенного давления катков 45 кН, рельс квадратного сечения $25 \times 25$ мм. Для численного исследования данной балки моделировалась разрезная ПБ, учитывался распределяющий эффект кранового рельса $l_{e f}=64$ мм.

Расчет НДС ПБ проведен для случаев эксцентричного приложения нагрузки 15 и 30 мм и без эксцентриситета. Величины эксцентриситетов определяли исходя из общих допусков на устройство и эксплуатацию крановых путей: предельное смещение оси рельса с оси стальной ПБ при устройстве крановых путей не должно превышать 15 мм. При техническом освидетельствовании в ходе эксплуатации были выявлены смещения более 30 мм.

Расчетная модель балки с сеткой на верхней полке для последовательного нагружения локально распределенной нагрузкой показана на рис. 26 . Такая сетка позволяет прикладывать нагрузку в любом месте по длине балки с разными значениями эксцентриситета, что позволяет оценить их влияние на уровень НДС балки. Для создания конечно-элементной модели исполь-

Таблица 1. Расчетные значения крановых нагрузок

\begin{tabular}{|l|c|c|c|}
\hline $\begin{array}{c}\text { Наименование и } \\
\text { обозначение силы }\end{array}$ & $\begin{array}{c}\text { Нормативное значение, } \\
\text { кН } \overline{\mathrm{P}}_{\text {max }}\end{array}$ & $\begin{array}{c}\text { Коэффициент } \\
\text { перегрузки, } \gamma_{f 1}\end{array}$ & $\begin{array}{c}\text { Расчетное } \\
\text { значение, кН }\end{array}$ \\
\hline $\begin{array}{l}\text { Вертикальное давление } \\
\text { колеса, } \overline{\mathrm{P}}\end{array}$ & 230 & 1,3 & 299 \\
\hline $\begin{array}{l}\text { Горизонтальное } \\
\text { давление колеса } \overline{\mathrm{T}} \text {. }\end{array}$ & 23 & 1,3 & 29,9 \\
\hline
\end{tabular}




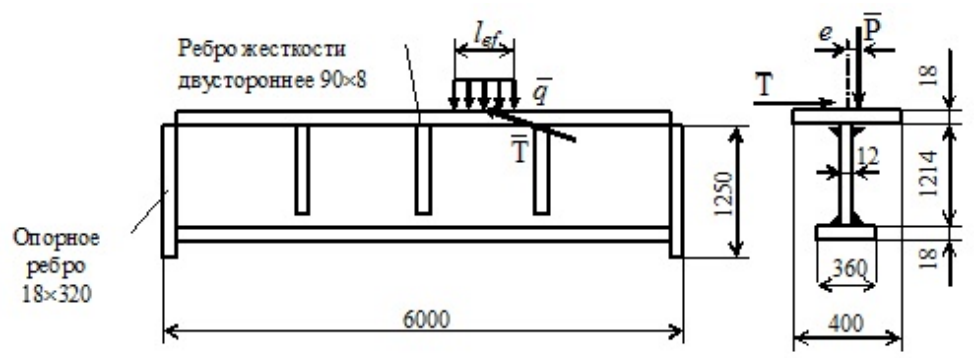

a)

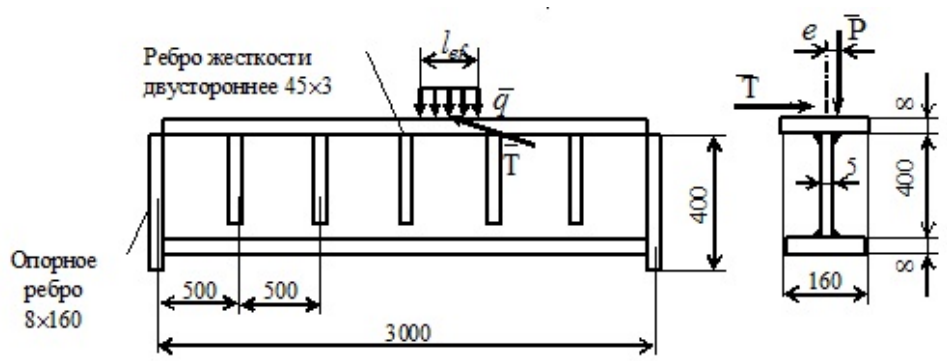

б)
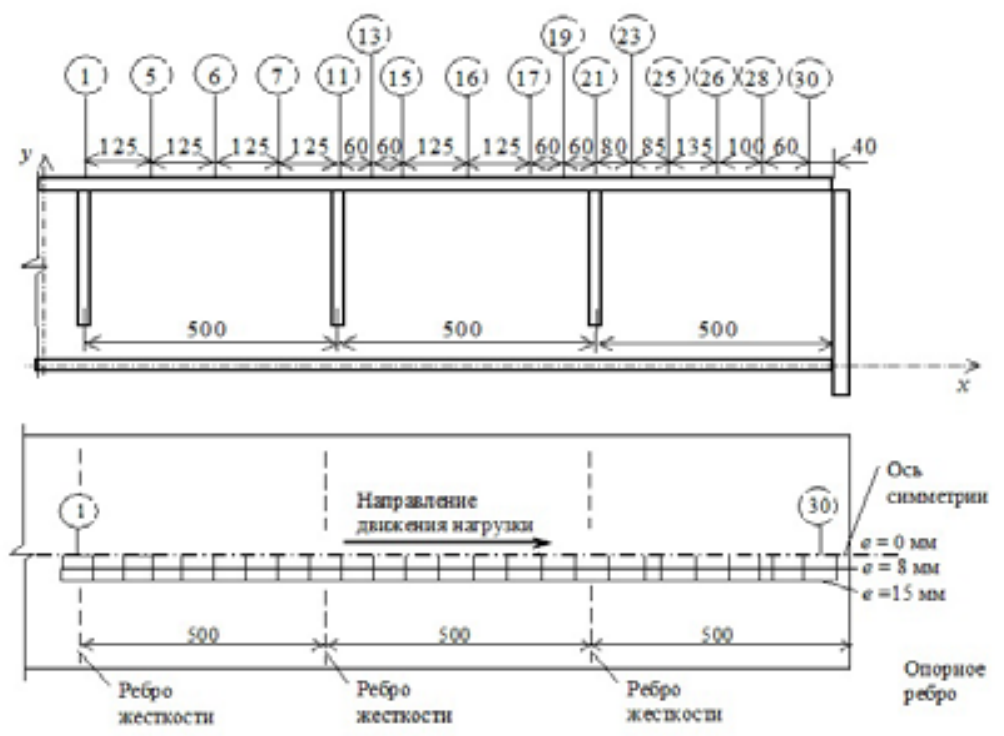

B)

Рис. 2. Геометрические размеры и схема нагружения подкрановых балок: а - проектная для электролизного цеха АО «КрАЗ»; б -для лабораторных испытаний в НГАСУ; в - расчетная модель 


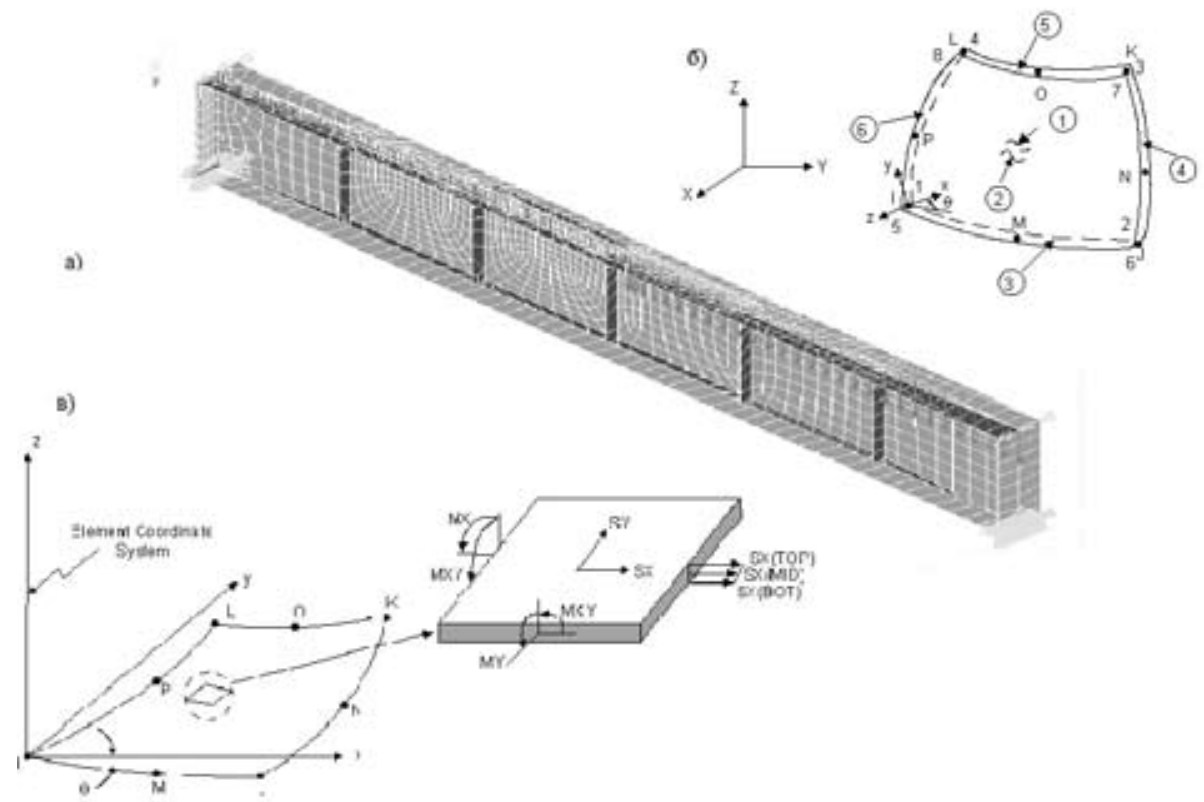

Рис. 3. Конечно-элементная модель подкрановой балки (а), конечный элемент SHELL93 (б) и система координат расчетных компонент напряжений (в)

зовали плоский изопараметрический элемент SHELL93. Этот элемент является четырехугольником с восемью узлами и имеет шесть степеней свободы (рис. 3). Конечно-элементная модель ПБ содержала 3188 элементов и 9623 узлов.

\section{2. Результаты модельных расчетов напряженно-деформированного состояния}

В результате проведенных расчетов НДС ПБ были получены:

- распределение интенсивности напряжений $\sigma_{i}$ по длине балки при разных величинах эксцентриситетов нагружения;

- распределения компонент напряженного состояния в сечении балки при ее нагружении одним колесом крана посередине отсека, ближайшего к центру ПБ.

На рис. 4 показано распределение интенсивности напряжений $\sigma_{i}$, возникающих в верхней зоне стенки (ВЗС) по длине ПБ при разных величинах эксцентриситетов нагружения. Анализ полученных результатов позволяет сделать ряд выводов:

- характер изменения интенсивности напряжений указывает на зависимость напряжений от величины эксцентриситета нагружения;

- максимальные значения интенсивности напряжений $\sigma_{i}$ зависят от конструктивных особенностей балки и возникают в приопорной зоне за счет повышенной жесткости балки в вертикальном направлении в зоне опорного ребра;

- минимальные значения интенсивности напряжений $\sigma_{i}$ возникают над ребром жесткости;

- значения интенсивности напряжений $\sigma_{i}$ в отсеках ПБ при их нагружении колесом крана посередине увеличиваются по мере приближения нагрузки к центру ПБ;

$$
-577-
$$


- напряжения, возникающие в ВЗС возле ребра жесткости, резко увеличиваются по сравнению с напряжениями, возникающими над ребром жесткости.

Анализ распределений интенсивности напряжений $\sigma_{i}$, возникающих в ВЗС в пределах одного отсека (рис. 4), показал, что их изменение происходит одинаково при всех значениях эксцентриситета в каждом отсеке. При нагружении балки колесом крана над ребром жесткости значения $\sigma_{i}$ минимальны, поскольку сечение, воспринимающее нагрузку, увеличивается за счет ребер жесткости. Как только колесо крана оказывается рядом с ребром жесткости, интенсивности напряжений, возникающие в ВЗС, резко возрастают за счет появления значительного

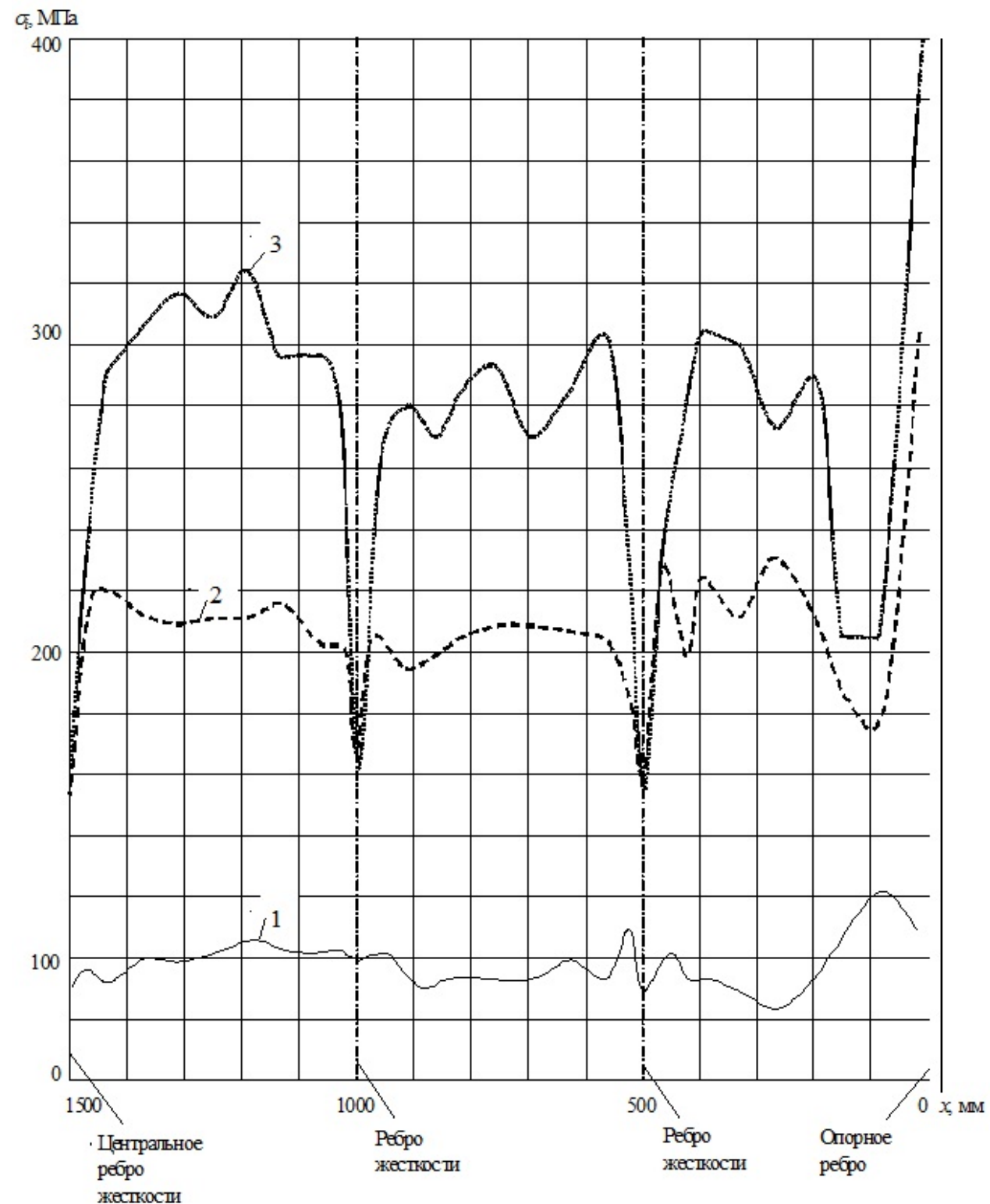

Рис. 4. Линии влияния интенсивности напряжений по длине подкрановой балки при разных эксцентриситетах: $1-e=0$ мм; $2-e=8$ мм; $3-e=15$ мм 
уровня касательных напряжений $\tau_{\text {ху. }}$ При дальнейшем движении нагрузки вдоль отсека значения напряжений несколько падают, однако при достижении нагрузкой середины отсека снова повышаются вследствие увеличения изгибающего момента стенки отсека из ее плоскости. Значительные уровни напряжений по сравнению со значениями, возникающими вдоль всей балки, появляются при ее нагружении возле ребра жесткости, ближайшего к опорному ребру.

Таким образом, анализ полученных распределений интенсивности напряжений в ВЗС ПБ показывает, что наибольшие значения напряжений возникают в случае нагружения колесом крана возле ребер жесткости, особенно возле опорного ребра. Это объясняет возникновение усталостных трещин непосредственно возле ребер жесткости при натурном эксперименте, проведенном в НГАСУ, и частое их выявление в этой области при проведении технических освидетельствований. Максимальные значения напряжений в случае $e=0$ мм возникают в опорном ребре в месте соединения стенки, нижнего пояса и опорного ребра. При технических освидетельствованиях в этом месте также выявляются усталостные трещины. При эксцентриситетах нагружения $e=8$ и 15 мм максимальные значения напряжений находятся в В3С непосредственно под зоной нагружения. В случае расположения колеса крана над ребром жесткости при наличии эксцентриситета максимальные значения появляются в зоне ребра жесткости, воспринимающего большую часть нагрузки.

\section{3. Влияние эксцентриситета приложения нагрузки}

Результаты численного исследования НДС показали, что в случае нагружения ПБ без эксцентриситета интенсивность напряжений, возникающих в проектной ПБ (рис. 5), находится в пределах 17,4 .. 71,9 МПа, что говорит об отсутствии напряжений, превышающих допускаемые значения. При эксцентриситете приложения нагрузки, равном 15 мм для проектной ПБ, величина интенсивности напряжений находится в пределах 12,4 .. 201,2 МПа, что также еще не превышает предела текучести стали. Такие уровни напряжений в условиях статического нагружения не оказывают существенного влияния на несущую способность балок, но при длительных периодах циклического нагружения возможно образование усталостных трещин. При эксцентриситете нагружения 30 мм интенсивность напряжений находится в пределах $10,7 \ldots$ 289,7 МПа. В этом случае уровни напряжений становятся недопустимыми для конструкций, работающих в условиях циклического нагружения. Максимальные касательные напряжения распределены в стенке балки так же, как интенсивность напряжений, и зависят от величины эксцентриситета приложения вертикальной нагрузки. Значения $\tau_{\max }$ при приложении нагрузки в сечении балки без эксцентриситета находятся в пределах 7,3 $\ldots 38,4 \mathrm{MПа,} \mathrm{при} e=15$ мм 6,6 ... 107,6 МПа, при $e=30$ мм - 5,7 ... 154,9 МПа.

По толщине стенки ПБ реализуется неоднородное напряженное состояние (рис. 6). С разных сторон стенки нормальные и касательные напряжения могут иметь не только разные значения, но и разные знаки. При увеличении эксцентриситета степень неоднородности повышается.

В ходе исследования НДС балки были построены эпюры распределения компонент напряженного состояния в сечении балки (рис. 7) при ее нагружении одним колесом крана посередине отсека, ближайшего к центру ПБ, поскольку в этом отсеке - согласно построенным линиям влияния (рис. 4) - возникают наибольшие значения интенсивности напряжения. Наибольшие

$$
-579-
$$




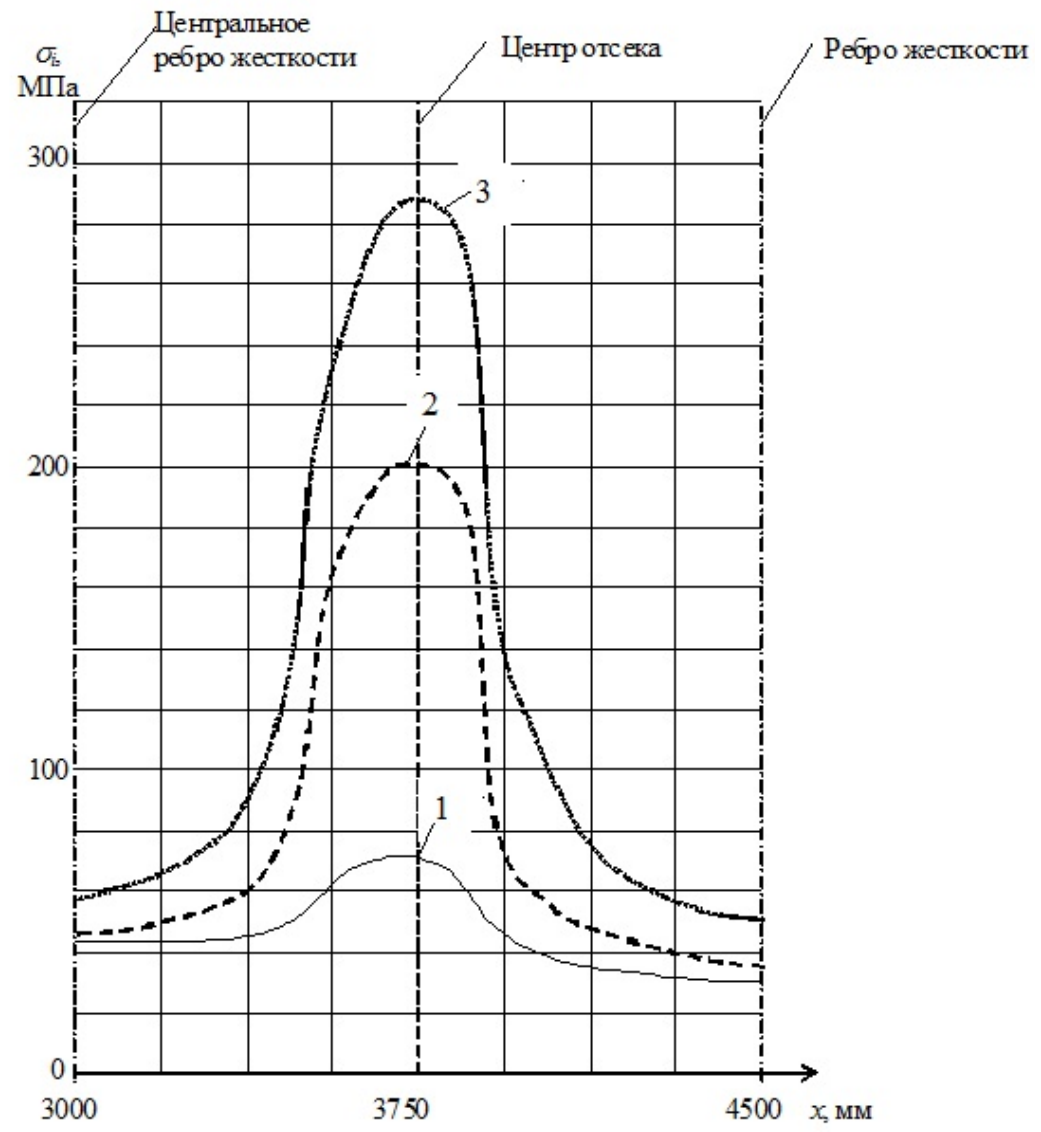

Рис. 5. Распределение интенсивности напряжений по длине одного отсека проектной подкрановой балки: $1-e=0 \mathrm{мм} ; 2-e=15 \mathrm{мм} ; 3-e=30 \mathrm{мм}$

значения максимальных нормальных и касательных напряжений наблюдаются в верхней зоне стенки ПБ (рис. 7), что и обуславливает возникновение и развитие трещин именно в этой зоне: непосредственно в сварном шве, который является концентратором напряжений, а также в металле стенки. При увеличении эксцентриситета увеличиваются значения максимальных касательных напряжений, следовательно, увеличивается опасность возникновения и ускоренного развития усталостной трещины.

\section{Заключение}

Проведенные расчеты позволяют сделать вывод о пропорциональной зависимости интенсивности напряжений ПБ, характеризующей ее сложное напряженное состояние, от эксцентриситета приложения нагрузки (рис. 8). Эксцентриситет приложения нагрузки оказывает существенное влияние на характер НДС ПБ: с увеличением эксцентриситета приложения нагрузки значения интенсивности напряжений, а следовательно, и максимальных касательных напряжений увеличиваются, что создает предпосылки для возникновения трещин усталости и указывает на необходимость более жестких ограничений на смещение рельса от оси симметрии балки и его контроль в процессе эксплуатации. 


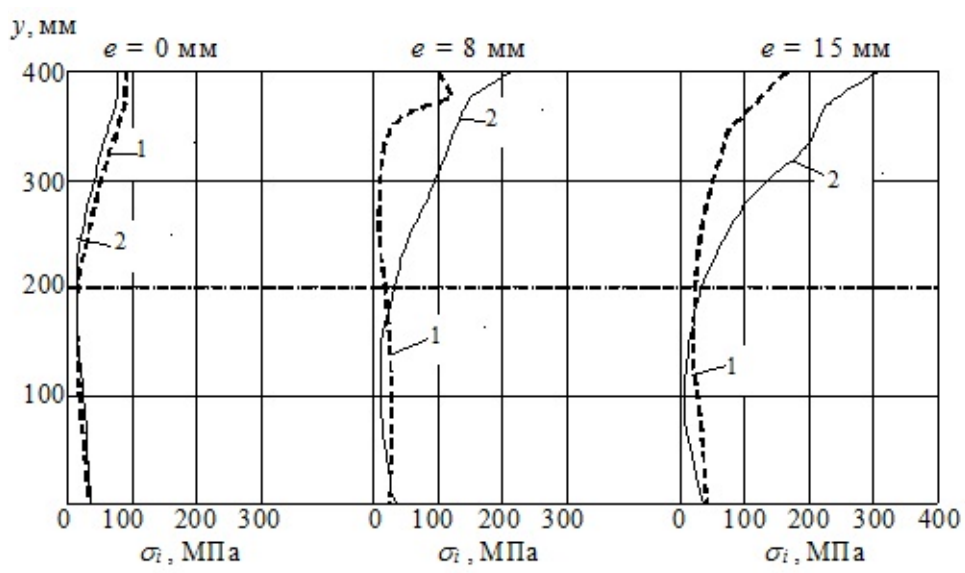

Рис. 6. Эпюры интенсивности напряжений при разных значениях эксцентриситета с разных сторон стенки ПБ: 1 - со стороны эксцентриситета; 2 - со стороны противоположной эксцентриситету

В результате численного анализа напряженно-деформированного состояния стенки ПБ при штатных режимах эксплуатации были установлены следующие закономерности:

- НДС стенки существенно зависит от величины эксцентриситета приложения крановой нагрузки;

- уровень интенсивности напряжений, возникающих в стенке балки, зависит от места приложения крановой нагрузки по длине балки;

- по толщине стенки возникает неоднородное напряженное состояние, степень неоднородности которого зависит от величины эксцентриситета.

Влияние эксцентриситета приложения крановой нагрузки, а также установленные особенности напряженно-деформированного состояния стенки подкрановой балки в зависимости от его величины (области неоднородного напряженного состояния, распределение максимальных значений интенсивности напряжений) могут являться основными отказообразующими факторами, приводящими к возникновению аварийных ситуаций. Полученные результаты были использованы при разработке нормативного документа «Руководство по определению индивидуального ресурса стальных подкрановых балок с усталостными трещинами в стенках для допущения их временной эксплуатации», разработанного ЗАО «ЦНИИПСК им. Мельникова». 


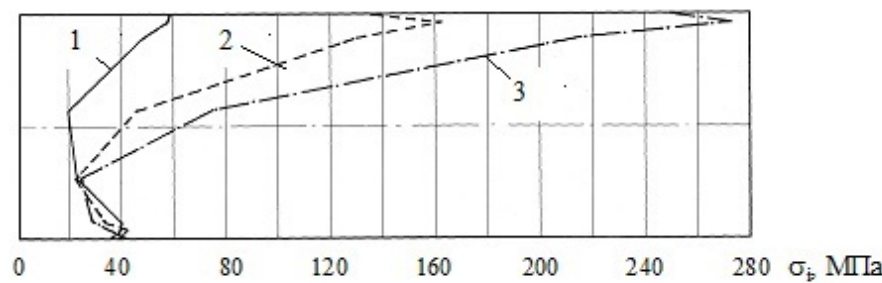

a)

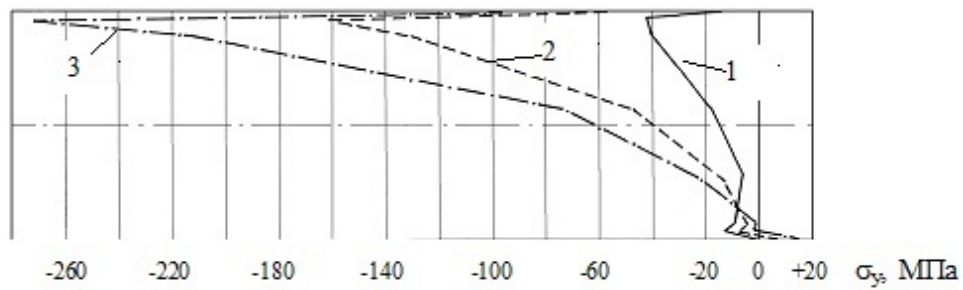

б)

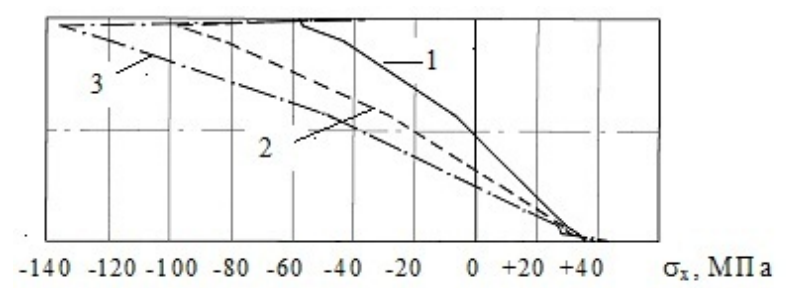

B)

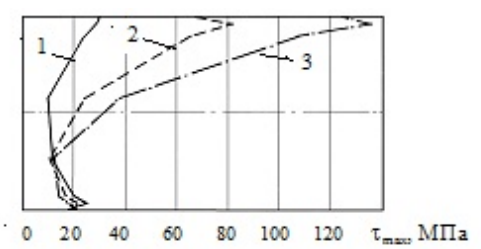

г)

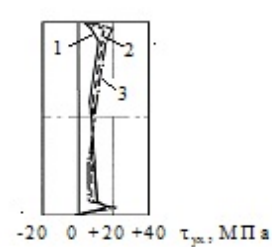

д)

Рис. 7. Распределение напряжений по высоте сечения подкрановой балки: интенсивность напряжений $\sigma_{i}(\mathrm{a})$; нормальные напряжения $\sigma_{y}\left(\right.$ б) и $\sigma_{x}\left(\right.$ в); максимальные касательные напряжения $\tau_{\max }(г)$; касательные напряжения $\tau_{y x}$ (д). $1-e=0$ мм; $2-e=15$ мм; $3-e=30$ мм

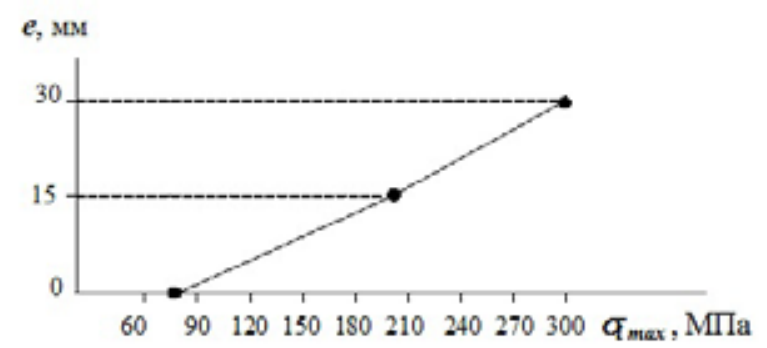

Рис. 8. Зависимость $\sigma_{i}$ от величины $е$ приложения вертикальной нагрузки 


\section{Список литературы}

[1] Москвичев, В. В. Основы конструкиионной прочности технических систем и инженерных сооружений: В 3 ч. Новосибирск: Наука, 2002. Ч. 1: Постановка задач и анализ предельных состояний. 106 с. [Moskvichev V. V. Fundamentals of structural strength of technical systems and engineering structures. In 3 p. Novosibirsk: Nauka, 2002. P. 1: Formulation and analysis of limit states. 106 p. (in Russian)]

[2] Малышкина, И. Н. Исследование напряженного состояния подкрановых балок. Промылиленное строительство. 1966, № 10, 29-32. [Malyishkina I. N. Investigation of the stress state of crane beams. Industrial Engineering, 1966, № 10, 29-32. (in Russian)]

[3] Симонов, В. И. Причины повреждения креплений подкрановых балок к колоннам. Промылиленное строительство. 1966, № 10, 22-24. [Simonov V. I. Causes of damage to fastenings of crane beams to the columns. Industrial Engineering, 1966, № 10, 22-24. (in Russian)]

[4] Хаютин, И. Л. О недостатках подкрановых балок. Промышленное строительство, 1966, № 9, 13-15.[Khayutin I. L. About the shortcomings of crane beams. Industrial Engineering, 1966, № 9,. 13-15. (in Russian)]

[5] Балдин, В. А. О причинах преждевременного выхода из строя подкрановых балок и вопросы их улучшения их конструкции. Промылиленное строительство. 1966, № 10,. 20-22. [Buldin V. A. The reasons of premature failure of the crane beams and their improve their design. Industrial Engineering, 1966, № 10,. 20-22. (in Russian)]

[6] Кикин, А. И., Эглескалн Ю. С. Результаты обследования подкрановых конструкций, запроектированных по действующим нормам. Промышленное строительство. 1968, № 12, 38-39. [Kikin A. I. The results of the survey of the crane structures designed according to current regulations. Industrial Engineering, 1968, № 12, 38-39. (in Russian)]

[7] Конаков, А. И., Махов А. П. Отказы и усиление строительных металлических конструкиий. Обзор. Вып. 4. М.: ВНИИПС, 1980, 52 с. [Konakov, А. I., Mahov A. P. Failures and strengthening of metal structures. Review. Vol. 4. M.: VNIIPI, 1980, 52 p. (in Russian)]

[8] Киневский, А. И. Повышение долговечности сварных подкрановых балок на основе исследований в условиях эксплуатаиии: автореф. дис. ... канд. техн. наук. Москва, 1983, 16 с. [Kinyevskiy, A. I. Increase of life of welded crane beams on the basis of research in operation: Author. dis. ... candidate. tech. sciences. Moskou, 1983, 16 p. (in Russian)]

[9] Беляев Б. И., Корниенко В. С. Причины аварий стальных конструкиий и способы их устранения. М.: Стройиздат, 1986, 67 с. [Byelyaev, B. I., Korniyenko V. S. Causes of accidents of steel structures and methods of their elimination. M.: Stroyizdat, 1986, 67 p. (in Russian)]

[10] Лащенко М. Н. Повышение надежности металлических конструкиий зданий и сооружений при реконструкиии. Л.: Стройиздат, 1987, 136 c. [Laschenko, M. N. Improving the reliability of metal structures of buildings and structures during reconstruction. L.: Stroyizdat, 1987, 136 p. (in Russian)]

[11] Хамшиашвили Р. В., Завьялов А. В. Дефекты монтажа стальных конструкций производственных зданий и сооружений. Промышленное строительство. 1991, № 10, С. 15-17. [Hamshiashvili R. V., Zavyalov A. V. Defects of installation of steel structures of industrial buildings and structures. Industrial Engineering, 1991, № 10, P. 15-17. (in Russian)]

[12] Фын Сю-Цзюнь, Линь Синь-Шань, Фан Тиан Исследование усталостных повреждений верхней зоны стенок стальных подкрановых балок. Промышленное и гражданское строи-

$$
-583-
$$


тельство. 1994, № 11-12, С. 33-35. [Fyn Su-Tsun, Lin Sin-Shan, Fan-Tian A study of the fatigue damage of the upper zone of the walls of steel crane beams. Industrial and Civil Engineering , 1994, № 11-12, P. 33-35. (in Russian)]

[13] Сабуров В. Ф. Особенности совместной работы крановых рельсов и подкрановых балок в подкрановых путях производственных зданий. Изв. вузов. Строительство. 1995, № 12, C. 8-13. [Saburov, V. F. Features use of crane rails, crane beams and crane runways in industrial buildings. Izvestiya vuzov. Construction, 1995, № 12, Р. 8-13. (in Russian)]

[14] Сергеев А. В., Шафрай С. Д. Влияние особенностей напряженного состояния в подкрановых балках на их прочность и выносливость. Изв. вузов. Строительство. 1997, № 7 , C. 9-12. [Sergyev A. V., Shafray S. D. The influence of the stress state in the beams of the crane in their strength and endurance. Izvestiya vuzov. Construction, 1997, № 7, P. 9-12. (in Russian)]

[15] Крылов И. И., Тарасевич В. В. Живучесть эксплуатируемых сварных подкрановых балок с усталостными повреждениями. Изв. вузов. Строительство. 1998, № 2, С. 17-25. [Krylov I. I., Tarasevich V. V. The persistence of exploited welded crane beams with fatigue damage. Izvestiya vuzov. Construction, 1998, № 2, P. 17-25. (in Russian)]

[16] О состоянии подкрановых конструкций корпуса конверторного производства ОАО «Северосталь» / В. Н. Артюхов, Е. А. Щербаков, В. М. Горицкий, Г. Р. Шнейдеров. Промышлленное и гражданское строительство. 2001, № 6, С. 31-34. [About the condition of crane structures housing BOF production of JSC «Severstal»/ V. N. Artyuhov, E. A. Scherbakov, V. M. Goritskiy, G. R. Shneyderov // Industrial and Civil Engineering, 2001, № 6, P. 31-34. (in Russian)]

[17] Чабан, Е. А., Цыплюк А. Н. Оценка ресурса подкрановых балок по данным технической диагностики. Труды научных мероприятий. Природно-техногенная безопасность Сибири: в 2 m. T. 2. Проблемы защиты населения и территорий от чрезвычайных ситуаций. Проблемы промышленной безопасности: Красноярск: ИПЦ КГТУ, 2001, С. 300-303. [Chaban E. A., Tsypluk A. N. Assessment of service life of crane beams according to technical diagnostics. Proceedings of scientific events. Natural-technogenic safety of Siberia: in 2 T. T 2. Problems of protection of population and territories from emergency situations. Problems of industrial safety: Krasnoyarsk: CPI KSTU, 2001, P. 300-303. (in Russian)]

[18] Закревский М. П. Анализ предельных состояний подкрановых балок / М. П. Закревский, В. В. Москвичев, В. С. Котельников, А. П. Черняев, Е. А. Чабан. Безопасность труда 6 промышленности. 2004, № 3, С. 31-33. [Zakrevskiy M. P. Analysis of limit states of the crane beams / M. P. Zakrevskiy, V. V. Moskvichev, V. S. Kotelnikov, A. P. Chernayev, E. A. Chaban // Safety in industry, 2004, № 3, P. 31-33. (in Russian)]

[19] Скляднев А. И., Сердюк В. В. Усталостная долговечность и мера повреждаемости верхней зоны стенки сварных подкрановых балок. Безопасность труда в промышленности. 2004, № 11, C. 34-36. [Skladnev A. I., Serduk V. V. Fatigue life and the measure of damage to the upper zone of the wall of welded crane beams. Safety in industry, 2004, № 11, P. 34-36. (in Russian)]

[20] Васюта Б. Н. К вопросу об определении напряжений в стенке от местного кручения пояса балки. Известия вузов. Строительство. 2006, № 3-4, С. 12-17. [Vasyuta B. ․ To the question about the determination of stresses in the wall of the local torsion of beams belt. Izvestiya vuzov. Construction, 2006, № 3 - 4, P. 12-17. (in Russian)] 